\title{
Response of vibration-isolated object to ground motions with intense vertical accelerations
}

\section{AUTHOR(S):}

Araki, Yoshikazu; Kawabata, Shinya; Asai, Takehiko; Masui, Takeshi

\section{CITATION:}

Araki, Yoshikazu ... [et al]. Response of vibration-isolated object to ground motions with intense vertical accelerations. Engineering Structures 2011, 33(12): 3610-3619

\section{ISSUE DATE:}

2011-12

URL:

http://hdl.handle.net/2433/149609

\section{RIGHT:}

(C) 2011 Elsevier Ltd.; This is not the published version. Please cite only the published version.; この論文は出版社版でありません。引用の際に は出版社版をご確認ご利用ください。 
Manuscript submitted for possible publication in Engineering and Structures

Response of vibration-isolated object to ground motions with intense vertical accelerations

by Y. Araki, S. Kawabata, T. Asai, T. Masui

\title{
Response of vibration-isolated object to ground motions with intense vertical accelerations
}

\author{
Yoshikazu Araki $^{\mathrm{a}^{*}}$, Shinya Kawabata ${ }^{\mathrm{a}}$, Takehiko Asai ${ }^{\mathrm{b}}$, Takeshi Masui ${ }^{\mathrm{c}}$
}

a Department of Architecture and Architectural Engineering, Kyoto University, Katsura, Nishikyo, Kyoto 615-8540, Japan

b Department of Civil and Environmental Engineering, University of Illinois at Urbana-Champaign, 205 N. Mathews Ave., Urbana, IL 61801, USA

c Department of Architecture, Kansai University, Yamatecho, Suita, Osaka 564-8680, Japan

* Correspondence author. Tel.:+81 753832924. E-mail address: araki@archi.kyoto-u.ac.jp

\section{Abstract}

This paper reports the results of shaking table tests performed to assess the response of an object placed on a vibration isolator to intense ground motions whose peak accelerations are close to or over the gravity acceleration in both vertical and horizontal directions. The passive vertical and horizontal vibration isolator, developed by the authors, has rolling load-bearing elements and constant-force springs to provide piecewise-constant restoring forces. First, we performed shaking table tests wherein only horizontal vibration was isolated. An unexpected finding from the tests is that, when the vibration isolator was subjected to ground motions with intense vertical accelerations, not only vertical but also horizontal accelerations were amplified. This led to large rocking response or overturning of the object placed on the vibration isolator. One likely reason of the amplification is rocking of the upper portion of the vibration isolator above the rolling load-bearing elements induced by intense vertical accelerations. Second, we performed shaking table tests wherein both vertical and horizontal vibrations were isolated. In this case, vertical as well as horizontal accelerations were significantly reduced and rocking response of the vibration-isolated object was suppressed. These results suggest potential risks in conventional horizontal vibration isolators having rolling load-bearing elements when they are subjected to ground motions with intense vertical accelerations. The results also demonstrate the effectiveness of vertical vibration isolation to avoid such risks.

\section{Key words}

Vibration isolation, Vertical ground motion, Rolling load-bearing element, Constant-force spring 
Manuscript submitted for possible publication in Engineering and Structures

Response of vibration-isolated object to ground motions with intense vertical accelerations

by Y. Araki, S. Kawabata, T. Asai, T. Masui

\section{Introduction}

In recent years, several intense ground motions have been recorded in Japan whose vertical peak ground accelerations (PGAs) were close to or over the gravity acceleration as shown in Table 1 [1, 2]. Among these earthquakes, 2004 Niigata-ken Chuetsu earthquake attracted considerable attention from the researchers and engineers in the field of passive vibration control. In this earthquake, a historic earthenware pot, a national treasure of Japan, turned over and broke into pieces while it was placed on a horizontal vibration isolator [3]. This accident posed a serious question on the reliability of vibration isolators because the horizontal vibration isolator was designed to work against the ground motions recorded in 1995 Hyogo-ken Nanbu earthquake, one of the most devastating earthquakes experienced in Japan. Two possible reasons were pointed out for the overturning. One was shortage of the stroke of the vibration isolator. The other was the influence of intense vertical accelerations.

After the accident, Kamba [3] performed shaking table tests to examine the response of objects placed on a horizontal vibration isolator to the ground motions recorded in 2004 Niigata-ken Chuetsu and 1995 Hyogo-ken Nanbu earthquakes. It was found from the tests that probability of the overturning of the objects to the JMA Ojiya ground motion, recorded in 2004 Niigata-ken Chuetsu earthquake, was significantly higher than that to the JMA Kobe ground motion, recorded in 1995 Hyogo-ken Nanbu earthquake, while the negative effect of the shortage of stroke of the horizontal vibration isolator was not observed throughout the tests. Based on these results and the PGA values of the ground motion records shown in Table 1, it was concluded that intense vertical accelerations were the likely reason of the higher probability of overturning. Nevertheless, vibration data, e.g., accelerations and displacements, are not reported in Reference [3] necessary for quantitative assessment of the reasons of the higher probability of overturning.

The accident and the increase of the number of ground motion records with intense vertical accelerations have led to an increasing demand for developing passive vertical vibration isolators to protect artworks and precision instruments from intense earthquake ground motions. Some research works dealt with the effect of horizontal vibration isolation on the response of vibration-isolated objects [4-8]. In addition, many types of passive vertical vibration isolators have been developed so far [9-17]. To the authors' knowledge, however, no literature reported experiments that examined the influence of vertical vibration isolation on the response of vibration-isolated objects when they are 
Manuscript submitted for possible publication in Engineering and Structures

Response of vibration-isolated object to ground motions with intense vertical accelerations

by Y. Araki, S. Kawabata, T. Asai, T. Masui

subjected to intense ground motions whose vertical and horizontal PGAs are both close to or over the gravity acceleration. The reasons of scarcity of such experiments can be considered as follows: (1) Most of the vertical vibration isolators developed so far were intended for isolating ambient or small vibrations and not for isolating intense earthquake ground motions. (2) Availability of strong ground motion records with intense vertical accelerations has been very limited.

The purpose of this paper is to examine the response of a vibration-isolated object when it is subjected to intense ground motions whose PGAs are close to or over the gravity acceleration in both vertical and horizontal directions. The vibration isolator, developed by the authors, has constant-force springs [18] to provide piecewise constant restoring forces in both vertical and horizontal directions. Note that the use of a combination of constant-force springs in vertical vibration isolation was originally proposed by Araki et al. [19]. The vibration isolator belongs to a class of passive nonlinear vibration isolators [16]. In this paper, two sets of shaking table tests are performed. First, we perform shaking table tests wherein only horizontal vibration is isolated. In this experiment, we study the influence of intense vertical accelerations on the response of an object placed on the vibration isolator by changing the level of the vertical components of input ground motions while fixing the level of the horizontal components. Next, we perform shaking table tests wherein vertical as well as horizontal vibrations are isolated. Through these tests, we examine the influence of vertical isolation on the response of the vibration-isolated object. Throughout this paper, the directions of vibration of the shaking table are restricted to vertical and horizontal two dimensions (2Ds) to simplify the experiment and analysis without loss of generality.

\section{Vibration isolator}

Fig. 1 schematically illustrates the present vertical and horizontal 2D vibration isolator. As shown in Fig. 1, the vibration isolator comprises two portions. The lower and upper portions work as horizontal and vertical vibration isolators, respectively. The upper portion has almost the same mechanism as the vertical vibration isolator reported in Reference [19]. The only improvement from the previous one is the addition of a link mechanism, indicated by the dotted box in Fig. 1, to avoid the rocking of the upper table of the vibration isolator. On the other hand, the lower portion has been newly developed so that it has piecewise-constant restoring forces similar to the vertical vibration isolator. This section 
Manuscript submitted for possible publication in Engineering and Structures

Response of vibration-isolated object to ground motions with intense vertical accelerations

by Y. Araki, S. Kawabata, T. Asai, T. Masui

summarizes the main mechanism of each portion.

The strengths of the present vibration isolator can be summarized as follows: (1) The use of constant-force springs allows us to easily realize long strokes while keeping the restoring-force mechanism simple and compact. (2) The vibration isolator has self-centering capability, which avoids accumulation of residual displacements in one direction during vibration. (3) In theory, the peak accelerations can be limited to a specified tolerance.

\subsection{Horizontal vibration isolator}

As illustrated in Fig. 2(a), the horizontal vibration isolator has linear guides and constant-force springs. The linear guides and have wheels inside them and work as rolling-bearing elements. Magnets are used to avoid the impact between the blocks connected to the table and those connected to the constant-force springs. The stiffness around the static equilibrium position is provided by the magnets. As shown in Fig. 3, a constant-force spring has constant restoring force regardless of its stretch. As shown in Fig. 2(b), the right constant-force springs provide the horizontal vibration isolator with the restoring force when the table moves to the right side. And the left constant-force springs provide the restoring force similarly when the table moves to the left side. The total capacities of the right and left constant-force springs are the same and denoted by $F_{h}$. Define by $u_{h}$ the horizontal relative displacement between the upper table and the base of the horizontal vibration isolator as shown in Fig. 2(b). Define by $k_{h}$ the stiffness around the static equilibrium position. Then the horizontal restoring force $f_{h}\left(u_{h}\right)$ can be written as

$$
f_{h}\left(u_{h}\right)=\left\{\begin{array}{cl}
F_{h} & \text { if } u_{h}>F_{h} / k_{h} \\
k_{h} u_{h} & \text { if }\left|u_{h}\right| \leq F_{h} / k_{h} . \\
-F_{h} & \text { if } u_{h}<-F_{h} / k_{h}
\end{array}\right.
$$

It should be noted that high-frequency response may be induced if $k_{h}$ is high. Assume regularized Coulomb's friction law. Let the over dot indicate differentiation with respect to time $t$. Define by $Q_{h}$ and $l_{h}$ the magnitude of the friction force and the initial viscous coefficient. Then the horizontal friction force $q_{h}\left(\dot{u}_{h}\right)$ can be expressed as 


$$
q_{h}\left(\dot{u}_{h}\right)=\left\{\begin{array}{ll}
Q_{h} & \text { if } \dot{u}_{h}>Q_{h} / l_{h} \\
l_{h} \dot{u}_{h} & \text { if }\left|\dot{u}_{h}\right| \leq Q_{h} / l_{h} \\
-Q_{h} & \text { if } \dot{u}_{h}<-Q_{h} / l_{h}
\end{array} .\right.
$$

Fig. 4 depicts the restoring force curves of the horizontal vibration isolator. Define by $m_{h}$ the total mass of the vibration-isolated object, the vertical vibration isolator, and the upper table of the horizontal vibration isolator. Then the equation of motion in horizontal direction can be expressed as

$$
m_{h}\left(\ddot{u}_{h}+\ddot{u}_{g h}\right)+c_{h} \dot{u}_{h}+q_{h}+f_{h}=0,
$$

where $c_{h}$ is the damping coefficient and $\ddot{u}_{g h}$ is the horizontal component of ground acceleration. Assume that $c_{h}$ is small enough. Then the possible peak $a_{h}$ of the horizontal acceleration $\ddot{u}_{h}+\ddot{u}_{g h}$ can be written as

$$
a_{h}=\frac{F_{h}+Q_{h}}{m_{h}}
$$

\subsection{Vertical vibration isolator}

Fig. 5 illustrates the mechanism of the vertical vibration isolator. As illustrated in Fig. 5(a), the vertical vibration isolator has upper and lower sets of constant-force springs. The vibration-isolated object is placed on a table suspended by the upper set of constant-force springs. Rotation of the table is prevented by the link elements connected below. A bar suspended by the lower set of constant-force springs also supports the table when the object is in static equilibrium. Note that the bar can move only downward from the initial position. A rubber tube, indicated by a gray solid line, is attached to the upper surface of the bar to provide finite stiffness, which reduces the high-frequency vibration due to the impact between the lower table and the bar [19].

Let $F_{v 1}$ and $F_{v 2}$ be the total capacities of the upper and lower sets of the constant-force springs, respectively. Define by $m_{v}$ the total mass of the vibration-isolated object, the table, and the link elements. Then the vertical isolator is designed so that

$$
F_{v 1}<m_{v} g<F_{v 1}+F_{v 2}
$$

is satisfied, where $g$ is the gravitation acceleration. With this arrangement, the object is supported by 
1 both upper and lower sets of constant-force springs when the object is in static equilibrium (Fig. 5(a)) or when it moves downward (Fig. 5(b)). When it moves upward as shown in Fig. 5(c), on the other hand, the table and the bar separates and the object is supported only by the upper sets of constant-force springs. The restoring force curve $f_{v}\left(u_{v}\right)$ can be written as

$$
f_{v}\left(u_{v}\right)= \begin{cases}F_{v 1}+F_{v 2}-m_{v} g & \text { if } u_{v}>\left(F_{v 1}+F_{v 2}-m_{v} g\right) / k_{v} \\ k_{v} u_{v} & \text { if }\left(F_{v 1}-m_{v} g\right) / k \leq u_{v} \leq\left(F_{v 1}+F_{v 2}-m_{v} g\right) / k_{v}, \\ F_{v 1}-m_{v} g & \text { if } u_{v}<\left(F_{v 1}-m_{v} g\right) / k_{v}\end{cases}
$$

where $u_{v}$ is the relative vertical displacement between the table and the base of the vertical vibration isolator as shown in Fig. 5(b), and $k_{v}$ is the stiffness around the static equilibrium position. Note that high-frequency response may be induced if $k_{v}$ is high. Assume that the friction force $q_{v}\left(\dot{u}_{v}\right)$ can be expressed as

$$
q_{v}\left(\dot{u}_{v}\right)= \begin{cases}Q_{v} & \text { if } \dot{u}_{v}>Q_{v} / l_{v} \\ l_{v} \dot{u}_{v} & \text { if }\left|\dot{u}_{v}\right| \leq Q_{v} / l_{v} \\ -Q_{v} & \text { if } \dot{u}_{v}<-Q_{v} / l_{v}\end{cases}
$$

where $Q_{v}$ is the magnitude of the friction force and $l_{v}$ is the initial viscous coefficient. The equation of motion in the vertical direction can then be written as

$$
m_{v}\left(\ddot{u}_{v}+\ddot{u}_{g v}\right)+c_{v} \dot{u}_{v}+q_{v}+f_{v}=0,
$$

where $c_{v}$ is the damping coefficient in the vertical direction and $u_{g v}$ is the vertical component of the ground displacement. Assume $c_{v}$ is small enough. Then the possible peak $a_{v}$ of the vertical acceleration $\ddot{u}_{v}+\ddot{u}_{g v}$ can be written as

$$
a_{v}=\frac{\max \left(F_{v 1}+F_{v 2}-m_{v} g+Q, m_{v} g-F_{v 1}+Q\right)}{m_{v}} .
$$

\section{Shaking table tests}

\subsection{Test setting}

Fig. 6 shows the photograph of the vibration-isolated object and the present vibration isolator placed 
Manuscript submitted for possible publication in Engineering and Structures

Response of vibration-isolated object to ground motions with intense vertical accelerations by Y. Araki, S. Kawabata, T. Asai, T. Masui

on the shaking table. In the shaking table test, steel plates of $14.7 \mathrm{~kg}$ are placed on the vibration isolator as a balancing weight. Then a wooden rectangular parallelepiped is placed on the steel plates as a vibration-isolated object. The weight and sizes of the object are $1.46 \mathrm{~kg}$ and $80 \mathrm{~mm}$ x $80 \mathrm{~mm}$ x 400 $\mathrm{mm}$, i.e., the aspect ratio (height/width) of the object is 5 . The nominal values of the physical parameters of the vibration isolator were as follows: $m_{h}=37.7 \mathrm{~kg}, F_{h}=7.84 \mathrm{~N}, m_{v}=14.7 \mathrm{~kg}$, $F_{v 1}=196 \mathrm{~N}$, and $F_{v 2}=19.6 \mathrm{~N}$.

In this paper, we describe two sets of shaking table tests. First, we describe the tests wherein only the horizontal vibration isolator is activated while the vertical vibration isolator is fixed, i.e., only horizontal vibration is isolated. Second, the tests are conducted by activating both horizontal and vertical vibration isolators, i.e., both horizontal and vertical vibrations are isolated. The same loading and measurement conditions are applied in the two sets of shaking table tests. The test conditions are determined by referencing the shaking table tests performed by Kamba [3] and the results of the preliminary shaking table tests using commercially available horizontal vibration isolators.

As the input ground motions, JMA Ojiya and K-Net Ojiya ground motions are selected. Both ground motions were recorded at the stations in Ojiya city in 2004 Niigata-ken Chuetsu earthquake. Fig. 7 shows the time histories of these ground motion records. Due to the limitations of the capacity of the shaking tables and the strokes of the horizontal vibration isolator, horizontal accelerations of JMA Ojiya and K-Net Ojiya ground motions are reduced to 0.7 and 0.6 times of the records. These scaling factors for the horizontal accelerations are kept constant throughout the test. On the other hand, the scaling factor $\Lambda$ for the vertical accelerations is changed as a parameter to examine the effect of vertical acceleration. In the shaking table tests, $\Lambda$ is set to $0,1.0$, and 1.2. To examine the repeatability of the test results, each ground shaking is applied 4 times when large rocking or overturning is observed because variability of response is usually very large when large rocking or overturning may take place.

Measurements of vibration data is performed at the points shown in Fig. 6. Accelerations are measured at point $\mathrm{T}$, and displacements are measured at points $\mathrm{T}, \mathrm{O} 1$, and $\mathrm{O} 2$. In addition, acceleration sensors are placed on the shaking table. Measurements of the displacements of the vibration isolators and the vibration-isolated object are conducted by using a non-contact digital image measurement system. The sampling rates of the measurements of accelerations and displacements are both $1000 \mathrm{~Hz}$. 
Manuscript submitted for possible publication in Engineering and Structures

Response of vibration-isolated object to ground motions with intense vertical accelerations by Y. Araki, S. Kawabata, T. Asai, T. Masui

\subsection{Results}

First, we show the results of the shaking table tests where only horizontal vibrations are isolated. Table 2 summarizes the response of the object placed on the upper table of the vertical vibration isolator. Here, the tolerance value of the maximum rotation angle for slight rocking (SR) response was 0.025 radian. When $\Lambda=0$, only slight rocking response was observed. When $\Lambda=1.0$ and 1.2, the response can be classified into the following 3 types as schematically illustrated in Fig. 8: (a) overturning, (b) large rocking response, and (c) small rocking response with twist, or rotation around the $z$ axis. Here, Fig. 8(a) shows the xyz axes. Note that twist reduces the aspect ratio of the object, which usually stabilizes the response. As typical responses of the vibration-isolated object, Fig. 9 depicts time histories of the rotation angle around the $y$ axis of the vibration-isolated object to K-Net Ojiya ground motions when $\Lambda=0$ and $\Lambda=1.2$. Video 1 shows the response in case of $\Lambda=1.2$. Figs. 10 and 11 illustrate the time histories of the measured response accelerations to K-Net Ojiya ground motions for $\Lambda$ is 0 and 1.2 , respectively.

Second, the results of the shaking table test are reported wherein both vertical and horizontal vibrations were isolated. Table 3 summarizes the response of the vibration-isolated object. In this case, only slight rocking response was observed throughout the test regardless of the value of $\Lambda$. Fig. 12 depicts time histories of the rotation angle of the vibration-isolated object to K-Net Ojiya ground motions when $\Lambda$ was 0 and 1.2. Video 2 shows the response in case of $\Lambda=1.2$. Figs. 13 and 14 illustrate the time histories of the response accelerations measured for $\Lambda=0$ and $\Lambda=1.2$, respectively.

\subsection{Discussions}

From the results of the two sets of shaking table tests, the following discussions can be made.

\subsubsection{Horizontal 1D isolation}

1. When $\Lambda=0$, i.e., when only the horizontal ground motion was applied, the horizontal acceleration was successfully isolated as shown in Fig. 10 (2nd graph). On the other hand, a large spike and fluctuations can be observed in the vertical acceleration (4th graph). The fluctuations 
Manuscript submitted for possible publication in Engineering and Structures

Response of vibration-isolated object to ground motions with intense vertical accelerations

by Y. Araki, S. Kawabata, T. Asai, T. Masui

observed in the vertical accelerations during large horizontal ground excitation seem to be caused by impact and friction due to $3 \mathrm{D}$ rocking motion of the upper portion of the vibration isolator above the rolling load-bearing elements. The large spike around $9 \mathrm{sec}$ is likely to be caused by unintended motion of the shaking table because similar spike is also observed by the acceleration sensor placed on the shaking table (3rd graph).

2. Considerable amplification of both vertical and horizontal acceleration was observed when $\Lambda=1.2$ as shown in Fig. 11. Although the reason of the amplification of horizontal acceleration is unclear, the impact and friction due to rocking of the upper table of the horizontal vibration isolator are possible reasons. It appears that the rocking of the upper table was induced by the intense vertical ground motion. This is because the horizontal acceleration measured on the vibration isolator (2nd graph) looks more similar to the vertical acceleration measured on the shaking table (3rd graph) than the horizontal acceleration measured on the shaking table (1st graph).

3. From Table 2 and Fig. 9, it can be observed that the intense vertical ground motions increased the potential of large rocking response and overturning of the object placed on the vibration isolator.

4. In some cases, twist was observed. This means that three-dimensional rocking of the vibration-isolated object took place. The possible reasons of the twist are considered as follows: (1) The excitation was not perfectly 2D. (2) The vibration-isolated object was not perfectly placed on the center of the table. (3) The shape, the mass distribution, and the surface characteristics at the base of the vibration-isolated object were not exactly uniform.

\subsubsection{Horizontal and vertical $2 D$ isolation}

1. When $\Lambda=0$, both the horizontal and vertical accelerations were successfully isolated as shown in Fig. 13.

2. When $\Lambda=1.2$, both the horizontal and vertical accelerations were reduced significantly as shown in Fig. 14. In this case, the vertical vibration isolator kept the vertical force, transmitted to the upper table of the horizontal vibration isolator, constant. It seems that the constantly kept vertical force suppressed rocking of the upper table of the horizontal vibration isolator, and avoided amplification of accelerations observed in the horizontal 1D isolation case. The reduction of accelerations was, however, not so large as in the case of $\Lambda=0$. It appears that rocking of the 
Manuscript submitted for possible publication in Engineering and Structures

Response of vibration-isolated object to ground motions with intense vertical accelerations by Y. Araki, S. Kawabata, T. Asai, T. Masui

upper portion of the vibration isolator remained, even though significantly suppressed, and the impact and friction caused by the rocking led to smaller reduction of accelerations.

3. From Table 3 and Fig. 12, vertical vibration isolation clearly decreased the potential of large rocking response and overturning of the vibration-isolated object.

\section{Numerical Simulations}

\subsection{Modeling}

The black lines in Fig. 15 show the horizontal and vertical restoring force curves obtained from static tests. In the static tests, the tables of the horizontal and vertical vibration isolators are moved by hands very slowly. And the displacement and the applied force are measured by a laser displacement sensor and load cell. We model these curves as shown by gray lines in Fig. 15. The values of the parameters obtained from the static test are as follows: $F_{h}=7.95 \mathrm{~N}, k_{h}=0.152 \mathrm{~N} / \mathrm{mm}, Q_{h}=3.87 \mathrm{~N}, F_{v 1}=177 \mathrm{~N}$, $F_{v 2}=23.4 \mathrm{~N}, \quad k_{v}=2.10 \mathrm{~N} / \mathrm{mm}, Q_{v}=11.7 \mathrm{~N}$. The errors in nominal and measured values of $F_{h}, F_{v 1}$, and $F_{v 2}$ are $1.40,9.69$, and $19.4 \%$, respectively. The damping parameters were determined by calibrating with the shaking table tests as $c_{h}=0.05 \mathrm{Nsec} / \mathrm{mm}, \quad c_{v}=0.01 \mathrm{Nsec} / \mathrm{mm}, \quad l_{h}=2 \mathrm{Nsec} / \mathrm{mm}$, and $l_{v}=1 \mathrm{Nsec} / \mathrm{mm}$. The Runge-Kutta time integrator provided by MATLAB is used to perform time history analysis [20].

\subsection{Results and discussions}

Figs. 16 and 17 show the comparisons of the time histories of accelerations and displacements, respectively, at the upper table of the vertical vibration isolator obtained from the shaking table tests and the numerical simulations when both horizontal and vertical vibrations are isolated. The horizontal and vertical peak accelerations predicted by Eqs. (4) and (9) are $0.31 \mathrm{~m} / \mathrm{sec}^{2}$ and $1.24 \mathrm{~m} / \mathrm{sec}^{2}$, respectively. These values are shown by gray lines in Fig. 16. Fig. 18 shows the comparisons of the response acceleration spectra of the ground motions and the motions at the upper table of the vibration isolated object (point T in Fig. 6).

From these figures, the following observations and discussions can be made. 
Manuscript submitted for possible publication in Engineering and Structures

Response of vibration-isolated object to ground motions with intense vertical accelerations

by Y. Araki, S. Kawabata, T. Asai, T. Masui

1. From Fig. 16, it is observed that the peak accelerations obtained from the shaking table tests are not reduced enough compared to the theoretical predictions and the predictions obtained by numerical simulations.

2. From Fig. 17, it can be observed that the displacement histories can be predicted by numerical simulations reasonably well, although numerical simulations predicts a little bit larger displacements in both directions.

3. From Fig. 18, it is seen that the response spectra are predicted by the simulation reasonably well except the high frequency range over $3 \mathrm{~Hz}$ and $12 \mathrm{~Hz}$ in horizontal and vertical directions, respectively. This means that the vibration isolators worked almost as we intended in the frequency range below the frequency values mentioned above.

4. The discrepancy between the numerical predictions and experimental results is an important issue. Hence one may point out that further numerical study is necessary where more detailed numerical models are used. Nonetheless, it is very difficult, if not impossible, to identify the main cause of the discrepancy only from numerical simulations because there are many sources of the discrepancy, e.g., impact, friction, 3D rocking, uncertainty in material constants, and very small clearances in rolling load-bearing elements and connections. Furthermore, it is difficult to make an appropriate numerical model even when only one of these sources is considered. For these reasons, we restricted ourselves to use simple numerical models for demonstrating that the vibration isolator worked as we intended at least in the low frequency range. Another reason for the use of simple numerical models is that isolation of low frequency vibration is usually important for avoiding large rocking and overturning of vibration-isolated objects caused by earthquake ground motions.

\section{Conclusions}

Through shaking table tests, we have examined the response of a vibration-isolated object placed on a horizontal and vertical 2D vibration isolator subjected to ground motions with intense vertical components close to or over the gravity acceleration. From the results of the shaking table tests where only horizontal vibration was isolated, it was observed that intense vertical ground motions clearly increased the risks of large rocking response or overturning of vibration-isolated objects. From the 
Manuscript submitted for possible publication in Engineering and Structures

Response of vibration-isolated object to ground motions with intense vertical accelerations by Y. Araki, S. Kawabata, T. Asai, T. Masui

results of the shaking table tests wherein both horizontal and vertical vibrations were isolated, it has been demonstrated that vertical vibration isolation was effective to significantly reduce such risks, although further study on suppression of high-frequency vibrations is still necessary. Examination of the influence of intense vertical ground motion by numerical simulation of 3D rocking motion of vibration-isolated objects is an important future research topic. Vibration isolation of larger scale structures and examination of effect of foundation rocking on 3D vibration isolation are also important future research topics.

\section{Acknowledgements}

This research was supported by Grant-in-Aid for Exploratory Research No. 19656138 provided by the Japan Society for the Promotion of Science (JSPS). Mr. Nobutoshi Yoshida helped to conduct the shaking table tests. The reviewers' comments led to significant improvements of the manuscript of this article. The authors gratefully acknowledge these supports.

\section{References}

[1] http://www.k-net.bosai.go.jp/k-net/topics/Iwatemiyaginairiku_080614/Iwatemiyaginairiku_08061 4.htm (Accessed 25 January 2011, in Japanese)

[2] http://www.k-net.bosai.go.jp/k-net/topics/maxpgapgv/pgav5v20070325.html (Accessed January 2011, in Japanese)

[3] N. Kamba, A study on the proper use of vibration isolators as a measure against earthquakes, In: Japan Society for the Conservation of Cultural Property (Ed.), Rescue Our Cultural Properties. Kubapuro, Tokyo, 2007, pp. 44-46. (in Japanese)

[4] Vestroni F, Di Cinto S. Base isolation for seismic protection of statues. In: Proc. the 12th world conference on earthquake engineering. 2000.

[5] Caliò I, Marletta M. Passive control of the seismic response of art objects. Eng Struct 2003;25:1009-18.

[6] Contento A, Di Egidio A. Investigations into benefits of base isolation for nonsymmetric rigid blocks. Earthq Eng Struct Dyn 2009;38:849-66. 
Manuscript submitted for possible publication in Engineering and Structures

Response of vibration-isolated object to ground motions with intense vertical accelerations by Y. Araki, S. Kawabata, T. Asai, T. Masui

[7] Di Egidio A, Contento A. Base isolation of sliding-rocking non-symmetyric rigid blocks subjected to impulsive and seismic excitations. Eng Struct 2009;31:2723-34.

[8] Di Egidio A, Contento A. Seismic response of a non-symmetric rigid block on a constrained oscillated base. Eng Struct 2010;32:3028-39.

[9] P. Alabuzhev, A. Gritchin, L. Kim, G. Migirenko, V. Chon, P. Stepanov, Vibration Protecting and Measuring Systems with Quasi-zero Stiffness. Hemisphere Publishing, NY, 1989.

[10] J. Winterflood, High performance vibration isolation for gravitational wave detection. Ph.D. Thesis, Department of Physics, University of Western Australia, 2001.

[11] E.I. Rivin, Passive Vibration Isolation. ASME Press, NY, 2003.

[12] D.C. Lagoudas, M.M. Khan, J.J. Mayes, B.K. Henderson, Pseudoelastic SMA spring elements for passive vibration isolation. J Intell Mater Sys Struct 2004;15:415-70.

[13] C.M. Lee, V.N. Voverdovski, A.I. Temnikov, Design of springs with "negative" stiffness to improve vehicle driver vibration isolation, J Sound Vib 2007;302:865-74.

[14] A. Carrella, Passive vibration isolators with high-static-low-dynamic-stiffness. Ph.D. Thesis, Faculty of Engineering, Science and Mathematics, Institute of Sound and Vibration, University of Southampton, 2008.

[15] R.H. Plaut, H.M. Favor, A.E. Jeffers, L.N. Virgin, Vibration isolation using buckled or pre-bent columns-Part 1: Two-dimensional motions of horizontal rigid bar, J Sound Vib 2008;310:409-20.

[16] R.A. Ibrahim, Recent advances in nonlinear passive vibration isolators, J Sound Vib 2008;314:371-452.

[17] I. Kovacic, M.J. Brennan, T.P. Waters, A study of a nonlinear vibration isolator with a quasi-zero stiffness characteristic, J Sound Vib 2008;315:700-11.

[18] F.A. Votta, Theory and design of long-deflection constant force spring elements. Transactions of the ASME 1952;74:439-50.

[19] Y. Araki, T. Asai, T. Masui, Vertical vibration isolator having piecewise-constant restoring force, Earthq Eng Struct Dyn 2009;38:1505-23.

[20] http://www.mathworks.com/help/techdoc/ref/ode23.html (Accessed 25 January 2011) 


\section{List of figures}

Fig. 1: Composition of vibration isolator.

Fig. 2: Mechanism of horizontal vibration isolator: (a) initial configuration and (b) deformed configuration $\left(u_{h}>0\right)$.

Fig. 3: Constant-force spring: (a) deformed configuration and (b) restoring force curve.

Fig. 4: Superposition of horizontal restoring force and friction force.

Fig. 5: Mechanism of vertical vibration isolator: (a) initial configuration, (b) deformed configuration $\left(u_{v}<0\right)$, and (c) deformed configuration $\left(u_{v}>0\right)$.

Fig. 6: Photograph of vibration isolator and vibration-isolated object and measurement points.

Fig. 7: Ground motion records.

Fig. 8: Classification of response of vibration-isolated object: (a) overturning, (b) large rocking response, and (c) twist.

Fig. 9: Measured rotation response of vibration isolated object (only horizontal vibration is isolated).

Fig. 10: Measured response accelerations (only horizontal vibration is isolated, $\Lambda=0$ ).

Fig. 11: Measured response accelerations (only horizontal vibration is isolated, $\Lambda=1.2$ ).

Fig. 12: Measured rotation Response of vibration isolated object (both horizontal and vertical vibrations are isolated).

Fig. 13: Measured response accelerations (both horizontal and vertical vibrations are isolated, $\Lambda=0$ ).

Fig. 14: Measured response accelerations (both horizontal and vertical vibrations are isolated, $\Lambda=1.2$ ).

Fig. 15: Restoring forces under static cyclic loading and their modeling.

Fig. 16: Comparison of time histories of (absolute) accelerations.

Fig. 17: Comparison of time histories of (relative) displacements.

Fig. 18: Comparison of response acceleration spectra. 
Manuscript submitted for possible publication in Engineering and Structures

Response of vibration-isolated object to ground motions with intense vertical accelerations

by Y. Araki, S. Kawabata, T. Asai, T. Masui

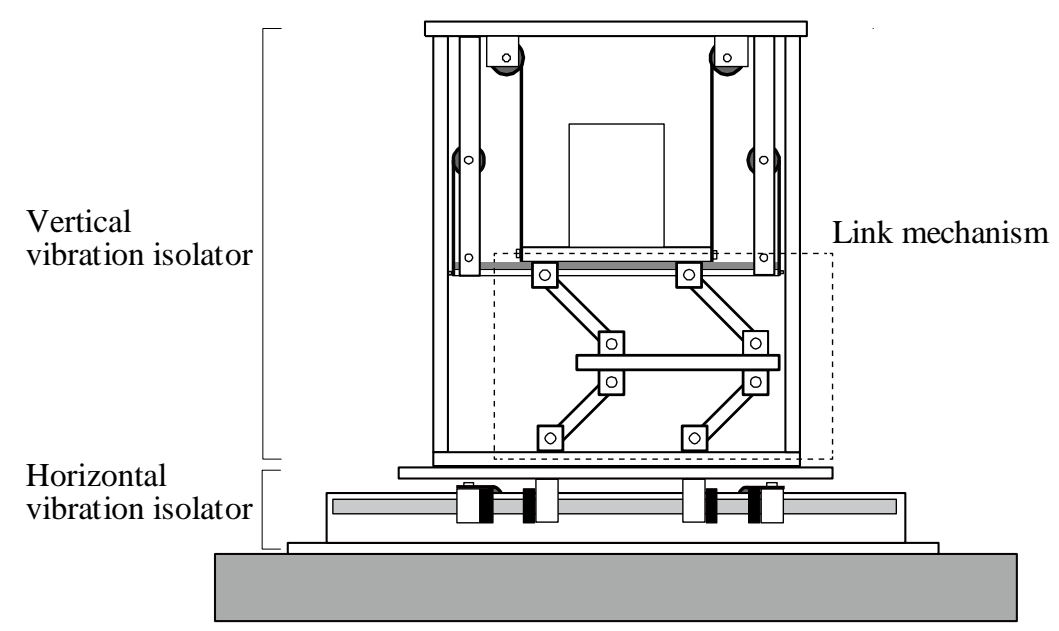

Fig. 1 


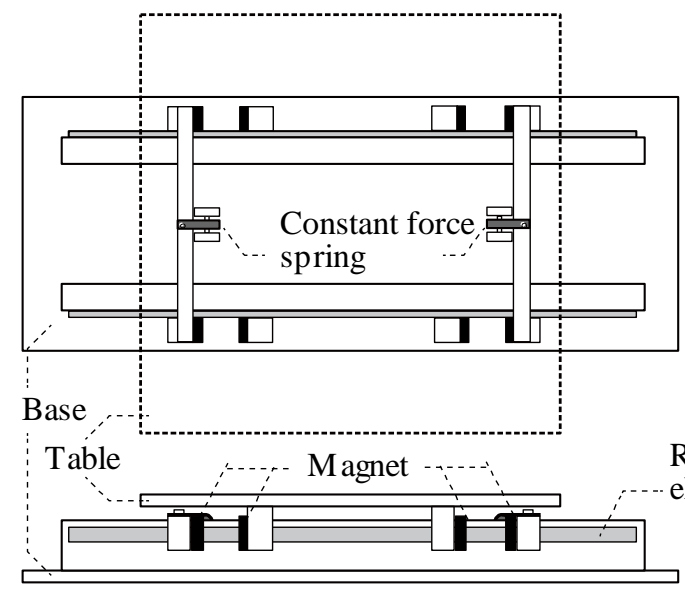

(a)

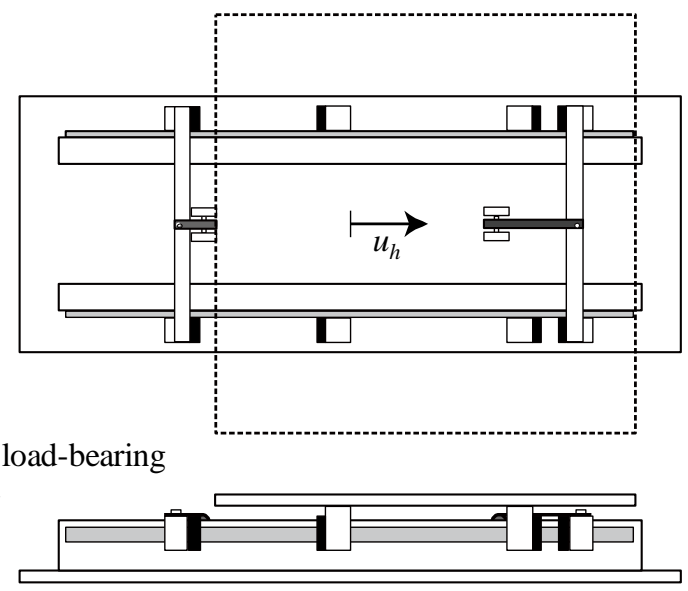

(b)

Fig. 2 
Manuscript submitted for possible publication in Engineering and Structures

Response of vibration-isolated object to ground motions with intense vertical accelerations

by Y. Araki, S. Kawabata, T. Asai, T. Masui

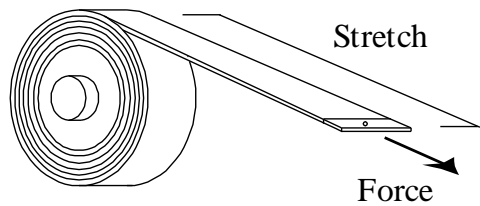

(a)

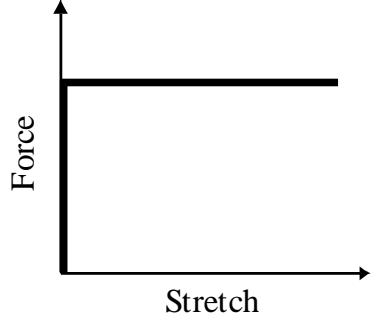

(b)

Fig. 3 
Manuscript submitted for possible publication in Engineering and Structures

Response of vibration-isolated object to ground motions with intense vertical accelerations

by Y. Araki, S. Kawabata, T. Asai, T. Masui

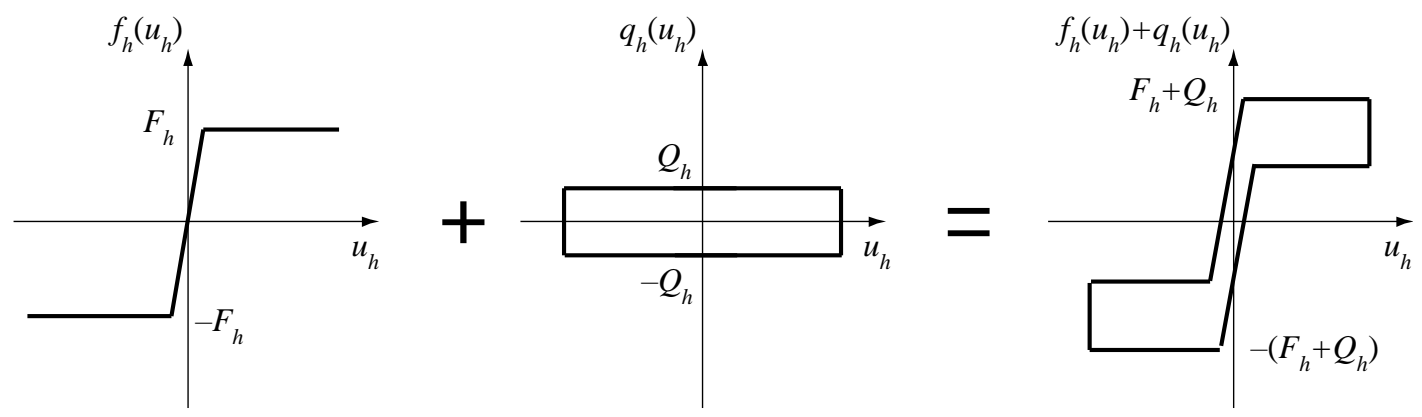

Fig. 4 


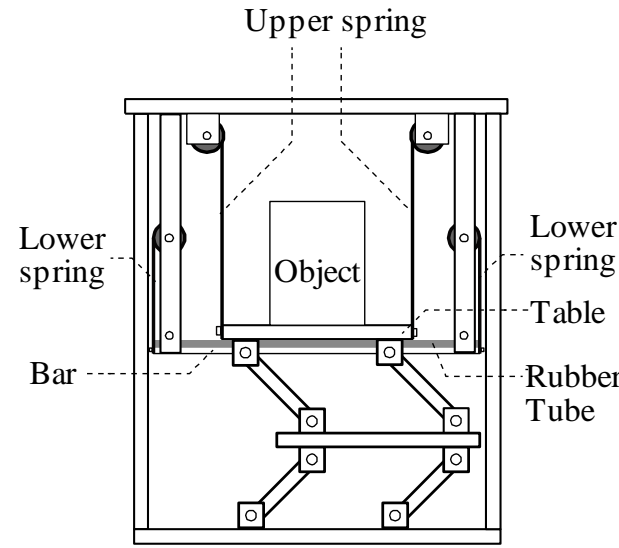

(a)

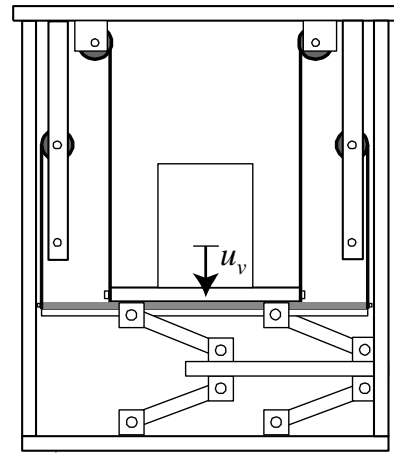

(b)

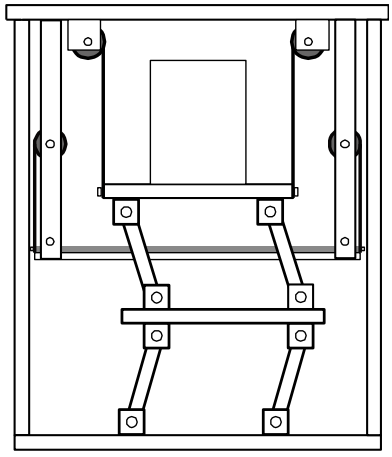

(c)

Fig. 5 
Manuscript submitted for possible publication in Engineering and Structures

Response of vibration-isolated object to ground motions with intense vertical accelerations

by Y. Araki, S. Kawabata, T. Asai, T. Masui

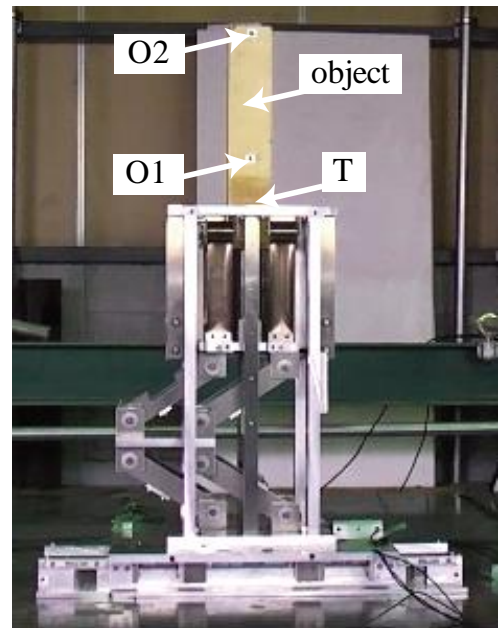

Fig. 6 

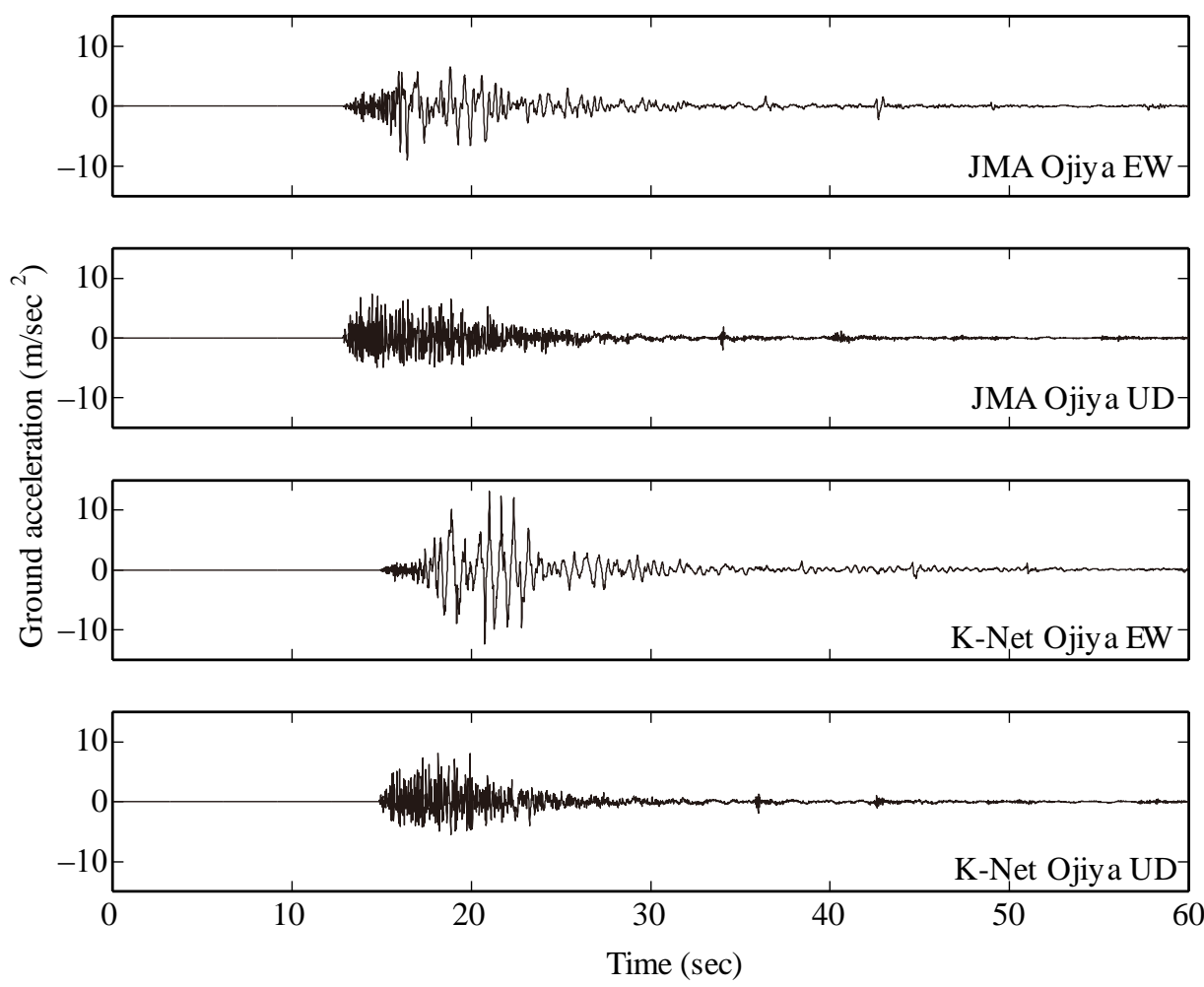

Fig. 7 
Manuscript submitted for possible publication in Engineering and Structures

Response of vibration-isolated object to ground motions with intense vertical accelerations

by Y. Araki, S. Kawabata, T. Asai, T. Masui

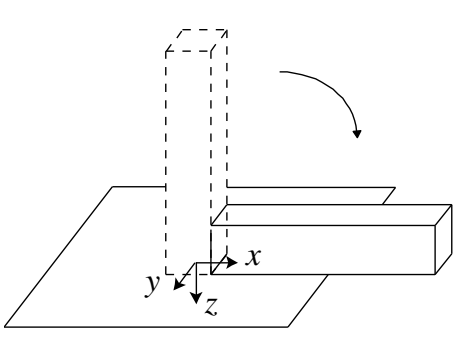

(a)

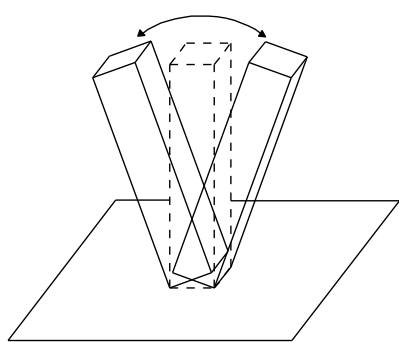

(b)

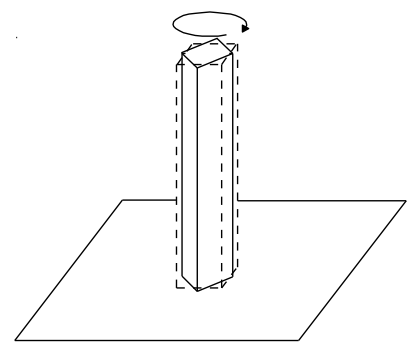

(c)

Fig. 8 
Manuscript submitted for possible publication in Engineering and Structures

Response of vibration-isolated object to ground motions with intense vertical accelerations

by Y. Araki, S. Kawabata, T. Asai, T. Masui

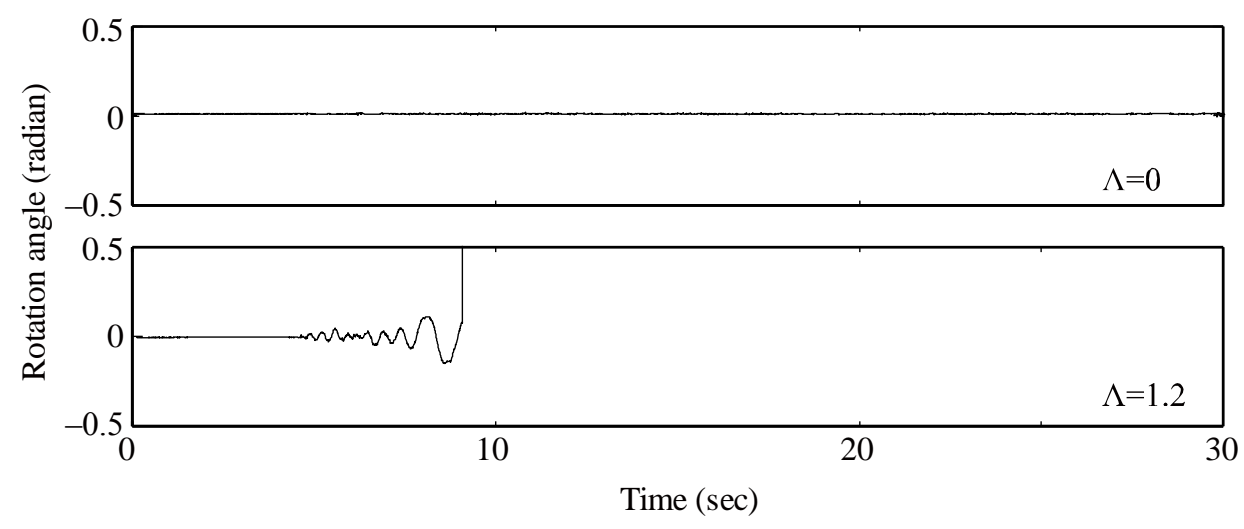

Fig. 9 

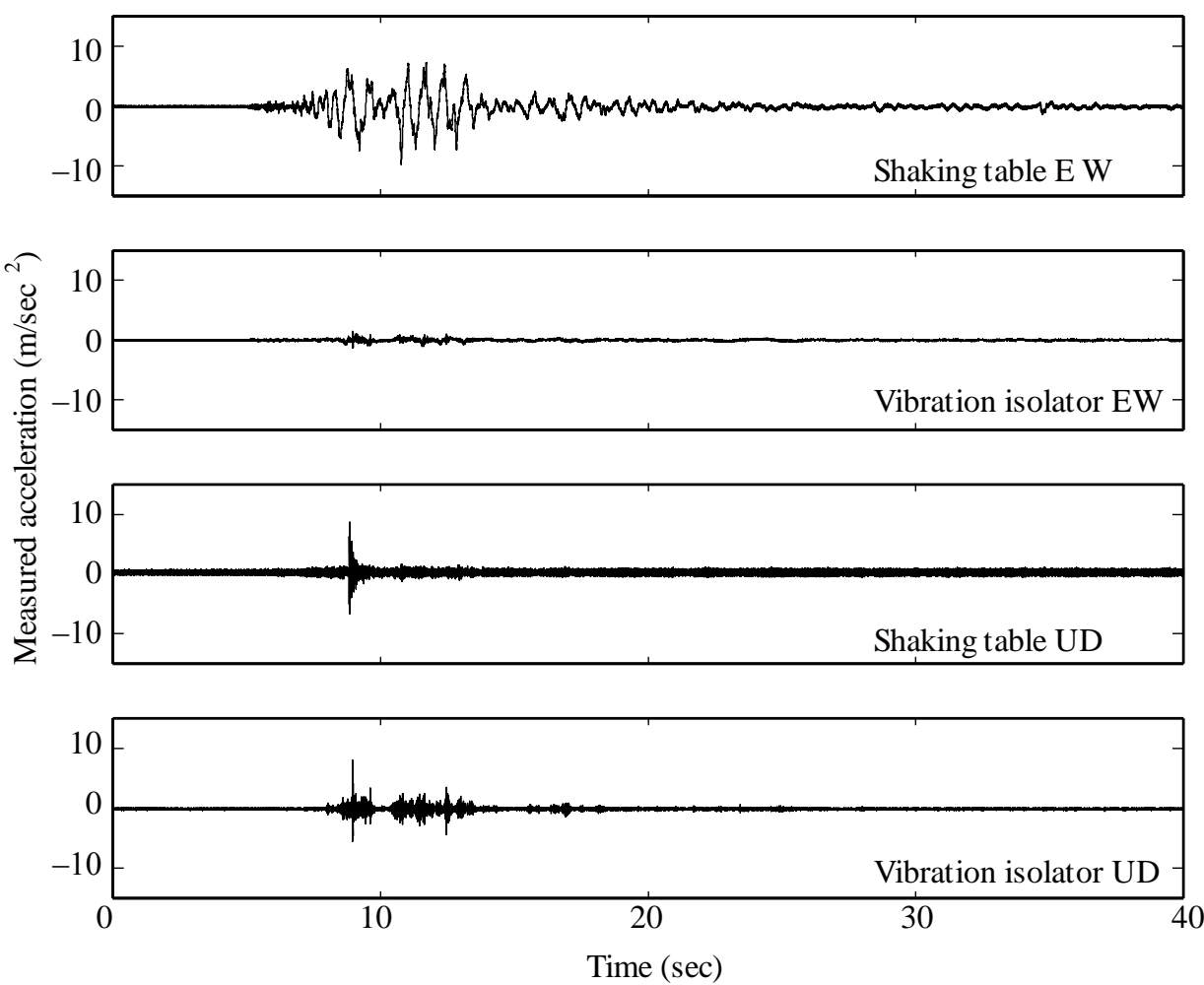

Fig. 10 

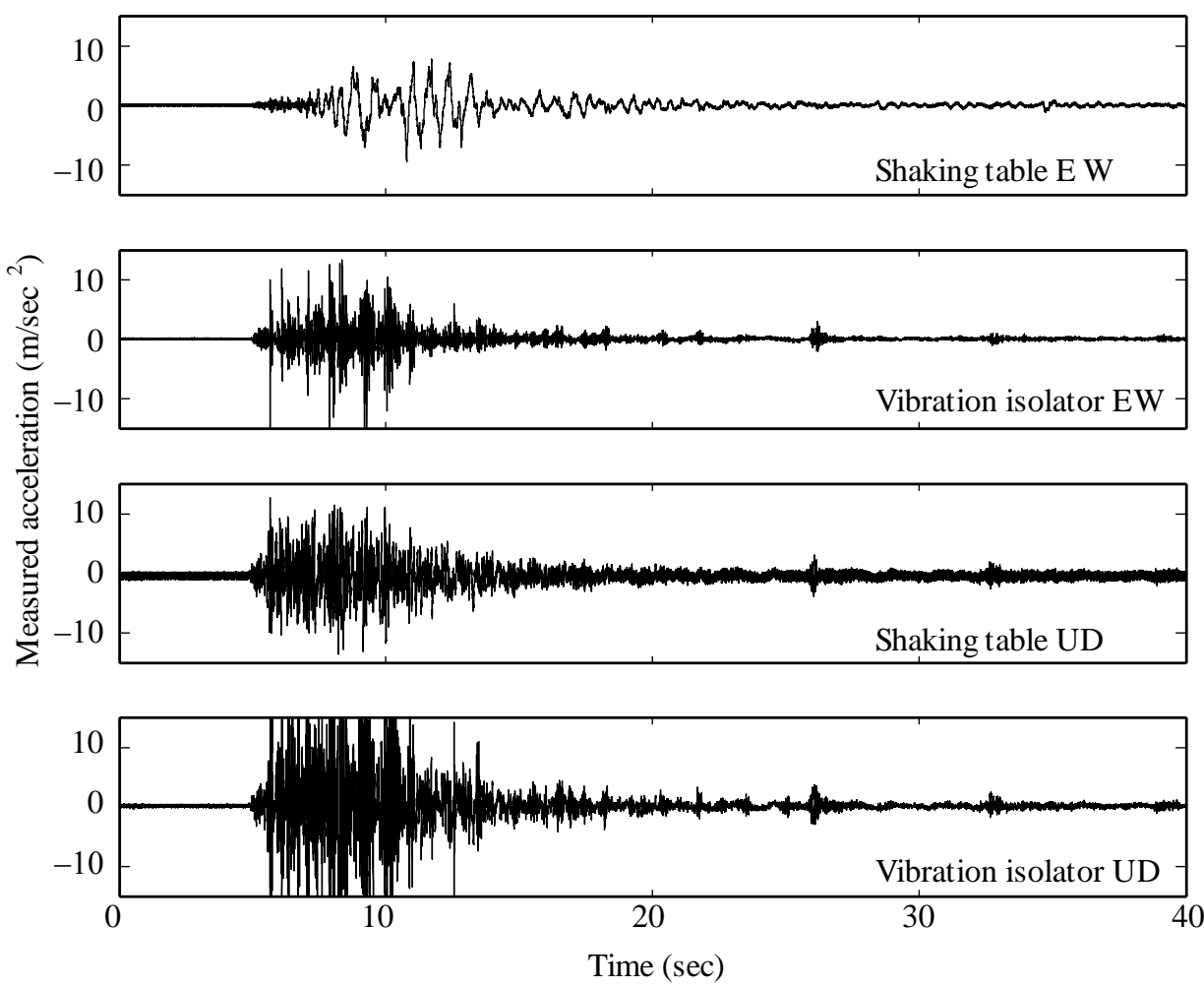

Fig. 11 
Manuscript submitted for possible publication in Engineering and Structures

Response of vibration-isolated object to ground motions with intense vertical accelerations

by Y. Araki, S. Kawabata, T. Asai, T. Masui

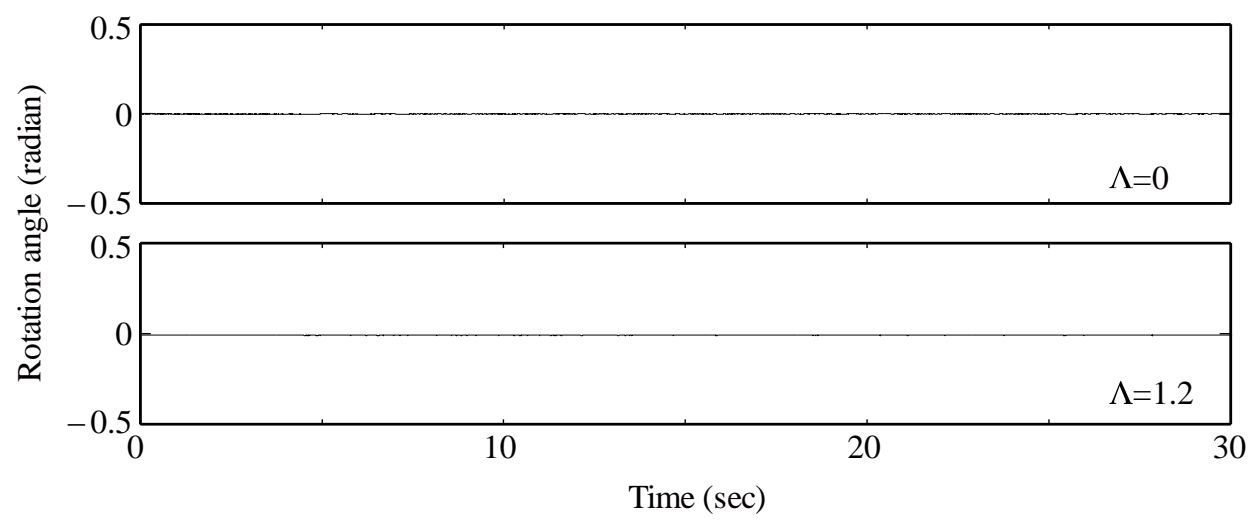

Fig. 12 

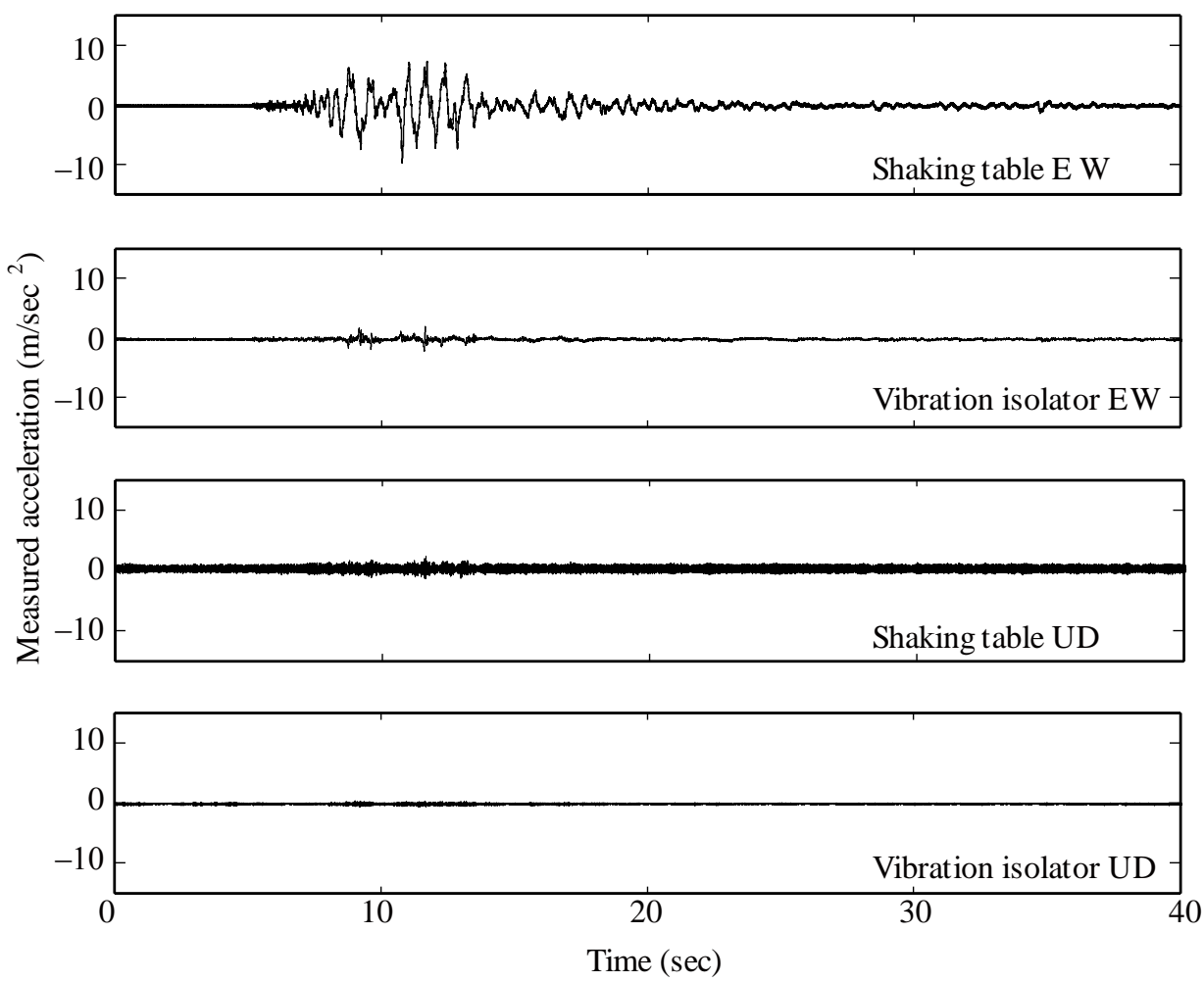

Fig. 13 

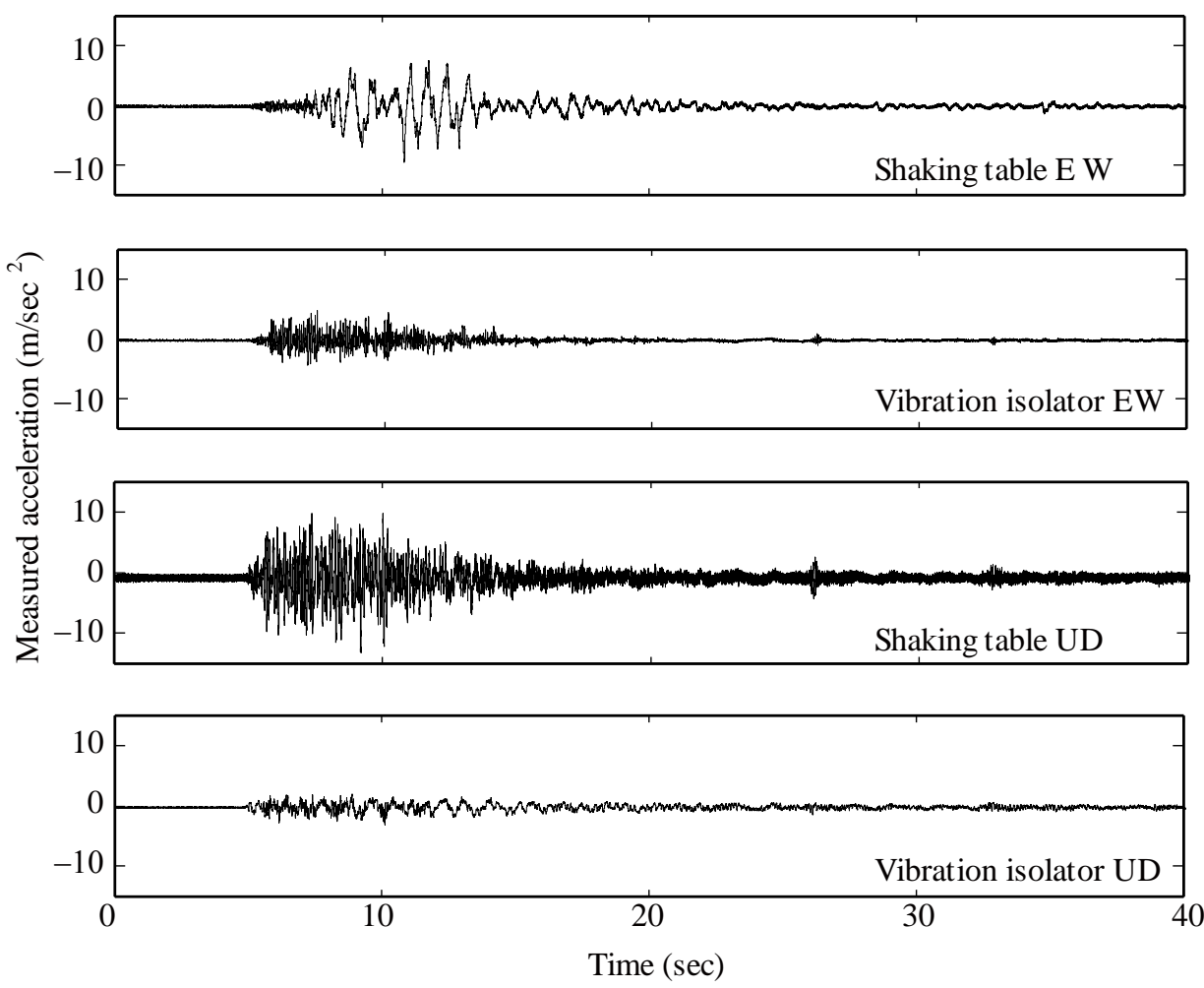

Fig. 14 

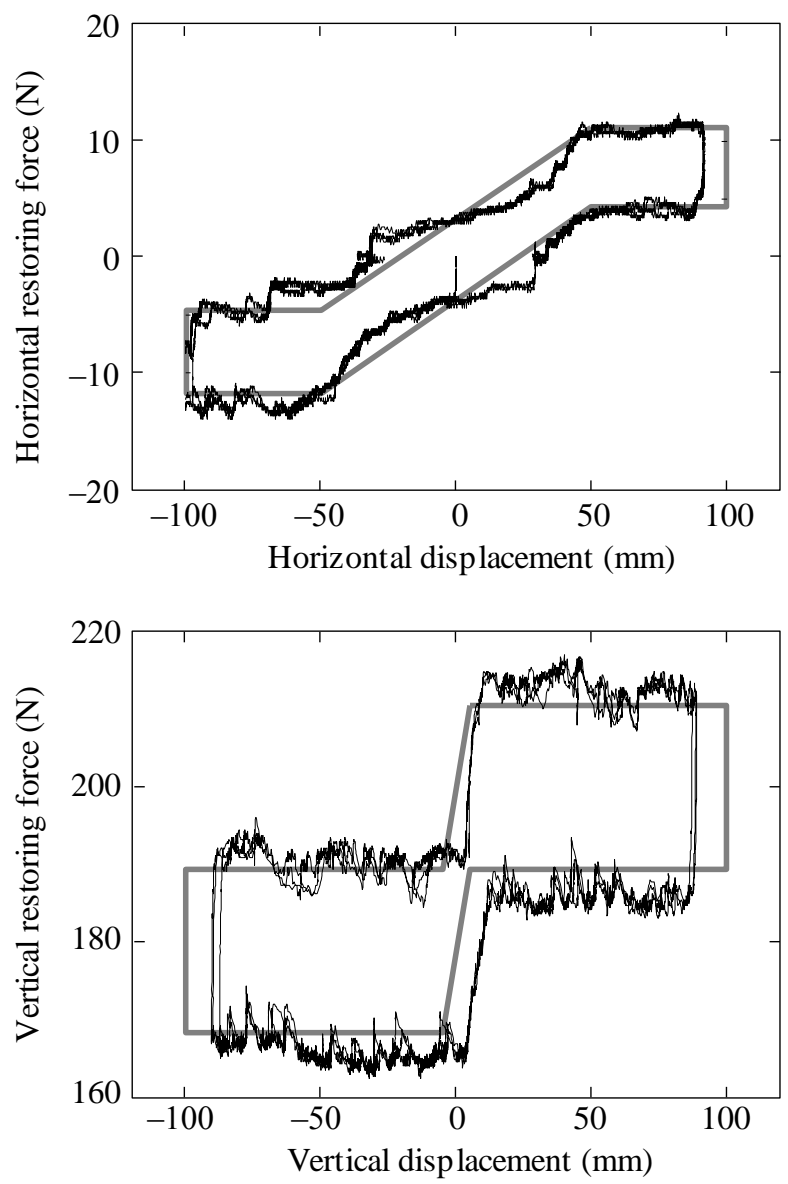

Fig. 15 
Manuscript submitted for possible publication in Engineering and Structures

Response of vibration-isolated object to ground motions with intense vertical accelerations

by Y. Araki, S. Kawabata, T. Asai, T. Masui
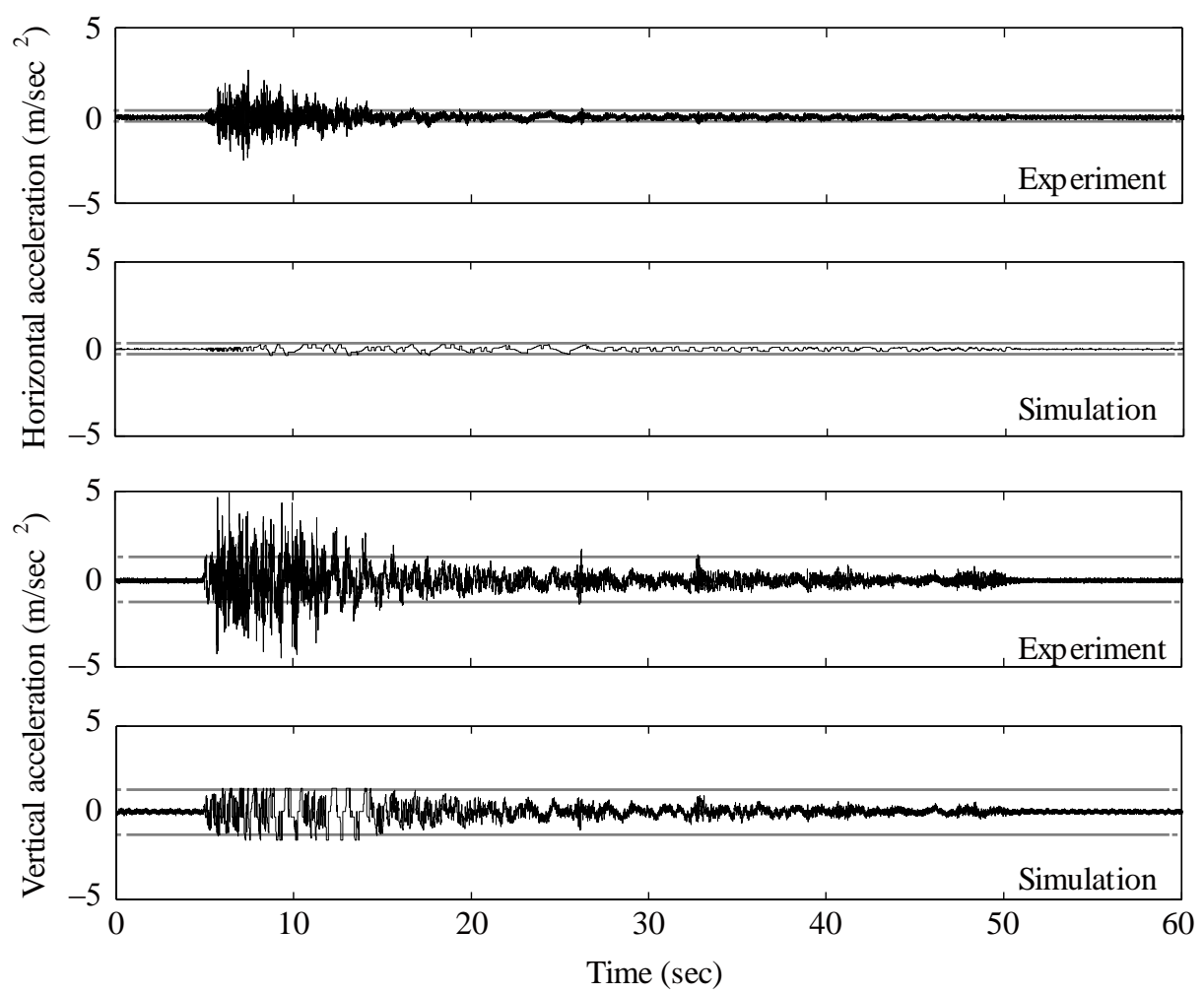

Fig. 16 
Manuscript submitted for possible publication in Engineering and Structures

Response of vibration-isolated object to ground motions with intense vertical accelerations by Y. Araki, S. Kawabata, T. Asai, T. Masui
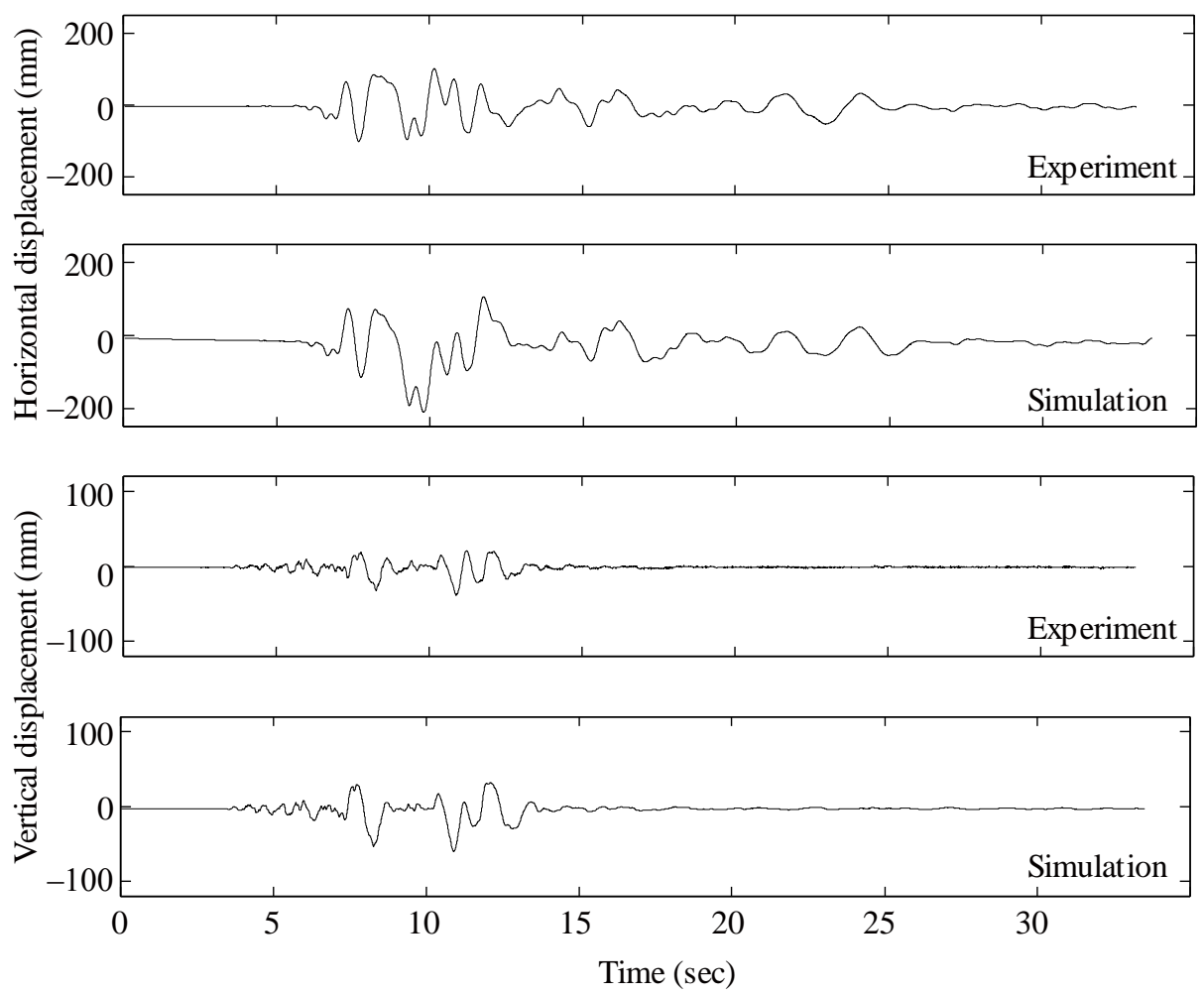

Fig. 17 
Manuscript submitted for possible publication in Engineering and Structures

Response of vibration-isolated object to ground motions with intense vertical accelerations

by Y. Araki, S. Kawabata, T. Asai, T. Masui

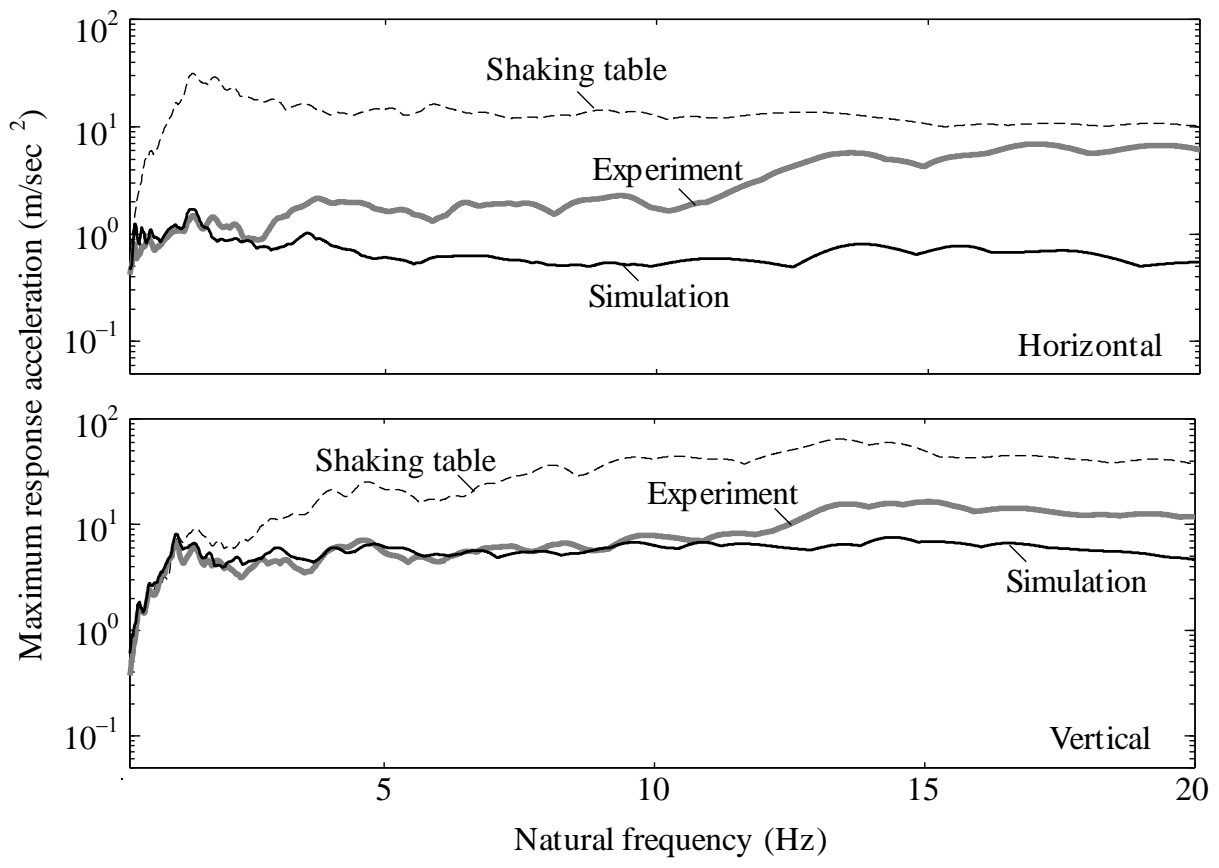

Fig. 18 


\section{List of tables}

Table 1: PGAs $\left(\mathrm{m} / \mathrm{sec}^{2}\right)$ of ground motion records.

Table 2: Response of vibration isolated object (only horizontal vibration is isolated).

Table 3: Response of vibration isolated object (both horizontal and vertical vibrations are isolated). 
Table 1

\begin{tabular}{cccccc}
\hline year & earthquake & Site & NS & EW & UD \\
\hline \multirow{2}{*}{2008} & Iwate-Miyagi-Nairiku & KiK-net IWTH25 & 11.43 & 14.33 & 38.66 \\
& & KiK-net AKTH04 & 24.48 & 13.19 & 10.95 \\
& & KiK-net IWTH26 & 10.54 & 8.89 & 9.28 \\
\multirow{2}{*}{2004} & Niigataken-Chuetsu & JMA Kawaguchi & 11.42 & 16.76 & 8.70 \\
& & JMA Yamakoshi & 5.24 & 7.22 & 10.59 \\
& & JMA Ojiya & 7.79 & 8.97 & 7.30 \\
2003 & Miyagi-ken Oki & K-NET NIG019 & 11.44 & 13.08 & 8.20 \\
& & KiK-net IWTH04 & 7.30 & 7.23 & 12.80 \\
1995 & Tottori-ken Seibu & KiK-net TTRH02 & 9.24 & 7.56 & 7.76 \\
& Hyogo-ken Nanbu & JMA Kobe & 8.18 & 6.17 & 3.32 \\
\hline
\end{tabular}

NS: North-South, EW: East-West, UD: Up-Down 
Table 2

\begin{tabular}{cccc}
\hline$\Lambda$ & Number of trial & JMA Ojiya & K-Net Ojiya \\
\hline 0 & 1 & SR & SR \\
1.0 & 1 & LR & LR \\
1.2 & 1 & OT & OT \\
1.2 & 2 & TW & TW \\
1.2 & 3 & LR & LR \\
1.2 & 4 & LR & OT \\
\hline
\end{tabular}

SR: Slight rocking, LR: Large rocking, OT: Overturning, TW: Small rocking with twist 
Manuscript submitted for possible publication in Engineering and Structures

Response of vibration-isolated object to ground motions with intense vertical accelerations

by Y. Araki, S. Kawabata, T. Asai, T. Masui

Table 3

\begin{tabular}{cccc}
\hline$\Lambda$ & Number of trial & JMA Ojiya & K-Net Ojiya \\
\hline 0 & 1 & SR & SR \\
1.0 & 1 & SR & SR \\
1.2 & 1 & TW & SR \\
\hline
\end{tabular}

SR: Slight rocking, TW: Small rocking with twist 
Manuscript submitted for possible publication in Engineering and Structures

Response of vibration-isolated object to ground motions with intense vertical accelerations

by Y. Araki, S. Kawabata, T. Asai, T. Masui

\section{List of videos}

Video 1: Response to K-Net Ojiya (only horizontal vibration is isolated, $\Lambda=1.2$ ).

Video 2: Response to K-Net Ojiya (both horizontal and vertical vibrations are isolated, $\Lambda=1.2$ ). 
Manuscript submitted for possible publication in Engineering and Structures

Response of vibration-isolated object to ground motions with intense vertical accelerations

by Y. Araki, S. Kawabata, T. Asai, T. Masui

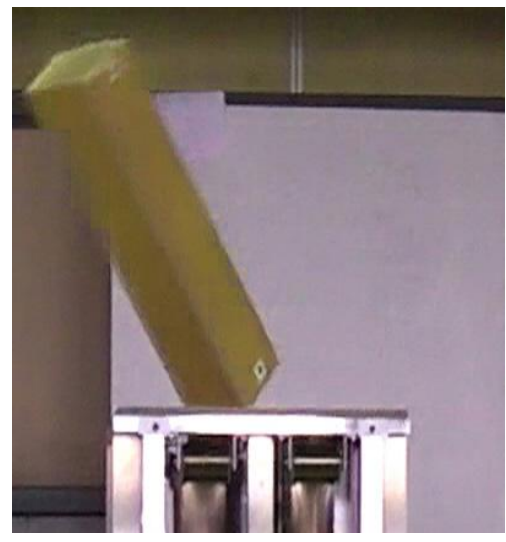

Video 1 
Manuscript submitted for possible publication in Engineering and Structures

Response of vibration-isolated object to ground motions with intense vertical accelerations

by Y. Araki, S. Kawabata, T. Asai, T. Masui

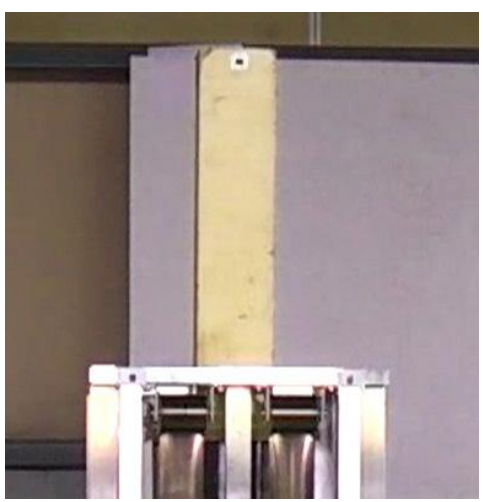

Video 2 